\title{
Jobbtilfredshet blant norske leger
}

\author{
Sammendrag \\ Bakgrunn. Legers jobbtilfredshet har \\ vært diskutert internasjonalt de senere \\ årene på bakgrunn av rapporter om \\ $ø$ kende profesjonell misnøye. Vi har \\ studert norske legers jobbtilfredshet \\ og generelle tilfredshet.
}

Materiale og metode. En spørreskjemaundersøkelse ble høsten 2008 utført blant et representativt utvalg yrkesaktive, norske leger. Jobbtilfredshet ble vurdert ved hjelp av måleinstrumentet Job Satisfaction Scale som inkluderer ti aspekter ved arbeidsforholdene.

Resultater. I alt 1072 leger (65\%) besvarte spørsmålene. Legene rapporterte en gjennomsnittlig jobbtilfredshet på 5,3 på en skala fra 1 (svært misfornøyd) til 7 (svært fornøyd). Jobbtilfredsheten økte med økende alder. Privatpraktiserende spesialister hadde høyest jobbtilfredshet $(5,8)$, og allmennleger $(5,5)$ høyere jobbtilfredshet enn sykehusleger $(5,1)$. Vurdert etter spesialitetsgrupper skåret samfunnsmedisinere høyest $(5,6)$ og leger i kirurgiske fag lavest $(5,0)$. Mens lang arbeidstid var negativt korrelert med jobbtilfredsheten, var det å ha bistilling(er) og opplevelsen av å være faglig oppdatert positivt korrelert. 52,9\% av legene anga meget høy generell tilfredshet.

Fortolkning. Norske leger har en høy grad av tilfredshet både med tilværelsen i sin alminnelighet og med jobben. Den generelle tilfredsheten med tilværelsen var minst på linje med den norske befolkningens.

\author{
Magne Nylenna \\ magne.nylenna@helsebiblioteket.no \\ Helsebiblioteket \\ Nasjonalt kunnskapssenter for helsetjenesten \\ Postboks 7004 St. Olavs plass \\ 0130 Oslo \\ og \\ Institutt for helse og samfunn \\ Universitetet i Oslo \\ og \\ Institutt for samfunnsmedisin
}

Norges teknisk-naturvitenskapelige universitet

\section{Olaf Gjerløw Aasland}

Legeforeningens forskningsinstitutt

og

Institutt for helse og samfunn

Universitetet i Oslo

Tilfredshetsforskning (happiness research) er et tverrfaglig vekstområde som engasjerer psykologer, sosiologer, filosofer, økonomer, medisinere og mange andre. Samfunnsforskeren Ottar Hellevik drøfter forskjellen mellom lykke og tilfredshet med tilværelsen, og påpeker at lykke dreier seg mest om følelser og sinnsstemning, mens tilfredshet handler mer om en vurdering av ulike sider ved tilværelsen. I prosjektet Norsk Monitor, en serie spørreundersøkelser i den norske befolkning fra 1985, måles de to fenomenene med ulike spørsmål, men for de fleste samsvarer svarene godt (1).

Arbeid er en av de viktigste faktorer for høy tilfredshet, sammen med familie, økonomi, venner, helse, personlig frihet og personlige verdier (2). I en arbeidssituasjon er autonomi, sammen med tillit mellom arbeidstaker og arbeidsgiver og deltakelse $\mathrm{i}$ beslutningsprosesser blant de forhold som øker tilfredsheten (3).

Mot slutten av 1990-tallet startet en debatt om legers jobbtilfredshet basert på flere publikasjoner som hevdet at tilfredsheten med legelivet var raskt synkende. Dette syntes først og fremst å være et amerikansk fenomen $(4,5)$. En Internett-basert undersøkelse arrangert av $B M J$ viste at to av tre leger erklærte seg som ulykkelige $(6,7)$.

En gjennomgang av den internasjonale litteraturen viser at de fleste publikasjoner om legers misnøye er debattinnlegg og lederartikler, og de få artiklene som bygger på egne data, er langt mindre entydige i sine konklusjoner $(8,9)$.

Her i landet viste Hofoss \& Nord i 1997 at det var færre leger enn andre som var svært tilfreds med arbeidet sitt (10). Finset og medarbeidere fulgte en gruppe norske medisinere fra studiestart til fire år etter eksamen, og fant da en gjennomsnittlig jobbtilfredshet på 5,2 på en skala fra 1 (svært misfornøyd) til 7 (svært fornøyd) (11). Tyssen og medarbeidere rapporterte i 2008 at norske leger hadde en noe lavere generell livstilfredshet enn tilsvarende grupper ikkeleger i befolkningen (12). Egne undersøkelser har vist en høy og stabil jobbtilfredshet blant norske leger helt fra 1994, da vi begynte med disse målingene (13). Allmennleger har vært mer tilfreds enn sykehusleger (14), og sykehusleger i Norge har hatt høyere tilfredshet enn sykehusleger i Tyskland (15).

For å oppdatere dette bildet gjennomførte vi en ny spørreskjemaundersøkelse høsten 2008. I tillegg til jobbtilfredshet studerte vi legenes generelle tilfredshet med tilværelsen. Målet var å undersøke norske legers aktuelle jobbtilfredshet, og å avdekke eventuelle systematiske forskjeller i tilfredshet mellom ulike legegrupper.

\section{Materiale og metode}

Siden 1994 har Legeforeningens forskningsinstitutt fulgt et representativt utvalg på opprinnelig 1200 yrkesaktive leger, det såkalte Referansepanelet, med spørreskjemaer omtrent hvert annet år. Etter hvert som noen leger ble pensjonister, ble de tatt ut av panelet, mens det i 2000 og 2008 er blitt supplert med et utvalg yngre leger som nylig hadde fått lisens.

I november 2008 ble et spørreskjema sendt til Referansepanelet, som da besto av 1662 leger. Det ble purret én gang til dem som ikke hadde svart etter tre uker.

\section{Variabler}

Legenes jobbtilfredshet ble kartlagt ved hjelp av måleinstrumentet Job Satisfaction Scale (JSS) (16). JSS bygger på ti aspekter ved arbeidsforholdene (ansvar, variasjon, forholdet

\section{Hovedbudskap}

- Norske leger har en høy grad av jobbtilfredshet og generell tilfredshet med tilværelsen

- Allmennleger har høyere jobbtilfredshet enn sykehusleger, og privatpraktiserende spesialister skårer høyest

- Jobbtilfredsheten øker med økende alder 
til kolleger, fysisk arbeidsmiljø, mulighet til å bruke egne evner, samlet jobbtilfredshet, frihet til å velge egne arbeidsmetoder, anerkjennelse, lønn og arbeidstid) som hvert skal skåres på en skala fra 1 (svært misfornøyd) til 7 (svært fornøyd). Total jobbtilfredshet beregnes som summen av alle ti skårer, uten vekting, som deles på ti og altså ligger mellom 1 og 7 for den enkelte lege.

I tillegg ble generell tilfredshet med tilværelsen (generelt velvære) målt med ett enkelt spørsmål: «Når du tenker på hvordan du har det for tiden, er du stort sett fornøyd med tilværelsen, eller er du stort sett misfornøyd?» Også dette spørsmålet ble skåret på en skala fra 1 (svært misfornøyd) til 7 (svært fornøyd).

Foruten kjønn og alder benyttet vi tre forskjellige inndelinger av legene.

- Bosted ble kategorisert i fem regioner (tab 1).

- Spesialitet ble kategorisert i seks grupper $i$ henhold til den grupperingen som ble etablert da Legekårsundersøkelsen startet i 1993 (17); allmennmedisin, laboratoriefag, indremedisinske fag, kirurgiske fag, psykiatri og samfunnsmedisin. Leger i spesialisering ble kategorisert etter den spesialitet de var under utdanning til, og leger med flere spesialiteter ble kategorisert $\mathrm{i}$ den spesialiteten de for tiden arbeidet i.

- Jobbsituasjon ble kategorisert i sykehus, allmennpraksis, privat spesialistpraksis, forskere (stipendiater, forskere og fulltidsprofessorer), administrasjon og annet.

\section{Statistikk}

Resultatene presenteres primært deskriptivt. Variasjoner i antall respondenter skyldes at ikke alle leger har svart på alle spørsmål. Vi benytter $95 \%$ konfidensintervaller (95\% $\mathrm{KI})$ for å teste eventuelle statistisk signifikante forskjeller mellom grupper. Gjennomsnitt er angitt for normalfordelte variabler, og median samt ikke-parametriske tester (Spearmans rho, Kruskal-Wallis test) for skjevfordelte variabler. For å sammenlikne generell tilfredshet mellom ulike grupper beregnet vi gjennomsnittlig rangering $\mathrm{i}$ gruppene med Kruskal-Wallis test. Vi benyttet en multivariat lineær regresjonsmodell med samlet jobbtilfredshet som responsvariabel og følgende prediktorer som vi mente kunne være relevante: kjønn, alder, antall barn, om ektefelle/samboer også er lege (ja/ nei), om legen har en bistilling i tillegg til hovedstillingen $(\mathrm{ja} / \mathrm{nei})$, antall timer som blir brukt ukentlig på faglig oppdatering, om legen opplever at hun/han greier å holde seg faglig oppdatert (ja/nei) og total ukentlig arbeidstid.

\section{Resultater}

I alt 1072 leger besvarte spørreskjemaet, 395 kvinner og 668 menn (ni leger har ikke oppgitt kjønn), noe som gir en responsrate på $65 \%$ (1 072/1 662). Medianverdiene for ge- nerell tilfredshet med tilværelsen, jobbtilfredshet, og de enkelte komponentene i jobbtilfredshetsskalaen fremgår av figur 1 . Samlet jobbtilfredshet for alle som har svart på alle ti spørsmål, var gjennomsnittlig 5,3 $(\mathrm{n}=1040)$.

\section{Jobbtilfredshet i ulike grupper}

Samlet jobbtilfredshet korrelerte med alder $(p<0,001, n=1039)$. Fordelingen av jobbtilfredshet etter kjønn, alder, bosted, spesialitet og jobbsituasjon er vist $i$ tabell 1 . Blant spesialitetsgruppene var samfunnsmedisinerne mest og kirurgene minst tilfredse. Blant jobbkategoriene var de privatpraktiserende spesialistene mest tilfredse. Forskerne lå lavest.

For enkeltspørsmålene i jobbtilfredshetsskalaen var mønsteret stort sett det samme i de forskjellige kategoriene, med noen unntak, særlig i forhold til spørsmålene om lønn og arbeidstid. Tabell 2 viser tilfredshet med lønn og arbeidstid. Når det gjelder tilfredshet med lønnen, lå forskerne i gjennomsnitt nesten 2 poeng lavere enn de privatpraktiserende spesialistene (skår 3,98 mot 5,85), og statistisk signifikant under alle de andre jobbkategoriene bortsett fra kategorien «annet», vurdert etter ikke overlappende konfidensintervall. Sykehuslegene var minst tilfreds med arbeidstiden.

\section{Andre forhold som kan påvirke jobbtilfredsheten}

Det var en svak negativ korrelasjon mellom samlet arbeidstid og jobbtilfredshet (Spearmans rho $=-0,061, \mathrm{p}=0,05, \mathrm{n}=1021)$. For det generelle velværemålet var denne sammenhengen betydelig sterkere ( $\mathrm{rho}=-0,119$, $\mathrm{p}<0,001, \mathrm{n}=1036)$. For fastlegene var det ingen sammenheng mellom listestørrelse og jobbtilfredshet $(p=0,84, n=241)$.

Tabell 1 Gjennomsnittsverdier for samlet jobbtilfredshet, målt med Job Satisfaction Scale, blant et utvalg norske leger i 2008 med $95 \%$ konfidensintervaller fordelt etter kjønn, alder, bosted, spesialitet og jobbsituasjon

\begin{tabular}{|c|c|c|}
\hline & Antall & $\begin{array}{c}\text { Gjennomsnitt } \\
\text { (95\% konfidensintervall) }\end{array}$ \\
\hline Kvinne & 381 & $5,22(5,14-5,31)$ \\
\hline Mann & 656 & $5,35(5,29-5,42)$ \\
\hline Totalt & 1037 & $5,31(5,25-5,36)$ \\
\hline Under 40 år & 303 & $5,15(5,06-5,24)$ \\
\hline 40-49 år & 247 & $5,16(5,03-5,27)$ \\
\hline $50-59$ år & 308 & $5,40(5,31-5,50)$ \\
\hline 60 år og eldre & 181 & $5,61(5,49-5,73)$ \\
\hline Totalt & 1039 & $5,31(5,25-5,36)$ \\
\hline Region 11 & 463 & $5,29(5,21-5,37)$ \\
\hline Region $2^{2}$ & 152 & $5,46(5,31-5,61)$ \\
\hline Region $3^{3}$ & 197 & $5,26(5,15-5,38)$ \\
\hline Region $4^{4}$ & 123 & $5,31(5,19-5,44)$ \\
\hline Region $5^{5}$ & 94 & $5,25(5,07-5,42)$ \\
\hline Totalt & 1029 & $5,31(5,26-5,36)$ \\
\hline Allmennmedisin & 258 & $5,54(5,45-5,63)$ \\
\hline Laboratoriefag & 80 & $5,46(5,30-5,61)$ \\
\hline Indremedisinske fag & 319 & $5,13(5,03-5,23)$ \\
\hline Kirurgiske fag & 182 & $5,02(4,89-5,16)$ \\
\hline Psykiatri & 126 & $5,37(5,21-5,52)$ \\
\hline Samfunnsmedisin & 35 & $5,60(5,33-5,87)$ \\
\hline Totalt & 1000 & $5,29(5,24-5,34)$ \\
\hline Sykehus & 578 & $5,10(5,03-5,17)$ \\
\hline Allmennlege & 269 & $5,53(5,44-5,63)$ \\
\hline Privatpraktisende spesialist & 61 & $5,79(5,63-5,95)$ \\
\hline Forskning & 64 & $5,41(5,22-5,60)$ \\
\hline Administrasjon & 41 & $5,60(5,33-5,86)$ \\
\hline Annet & 29 & $5,40(5,01-5,79)$ \\
\hline Totalt & 1042 & $5,30(5,25-5,35)$ \\
\hline \multicolumn{3}{|c|}{$\begin{array}{l}{ }^{1} \emptyset \text { stfold, Akershus, Oslo, Hedmark, Oppland } \\
{ }^{2} \text { Buskerud, Vestfold, Telemark, Aust-Agder, Vest-Agder } \\
{ }^{3} \text { Rogaland, Hordaland, Sogn og Fjordane } \\
{ }^{4} \text { Møre og Romsdal, Sør-Trøndelag, Nord-Trøndelag } \\
{ }^{5} \text { Nordland, Troms, Finnmark }\end{array}$} \\
\hline
\end{tabular}




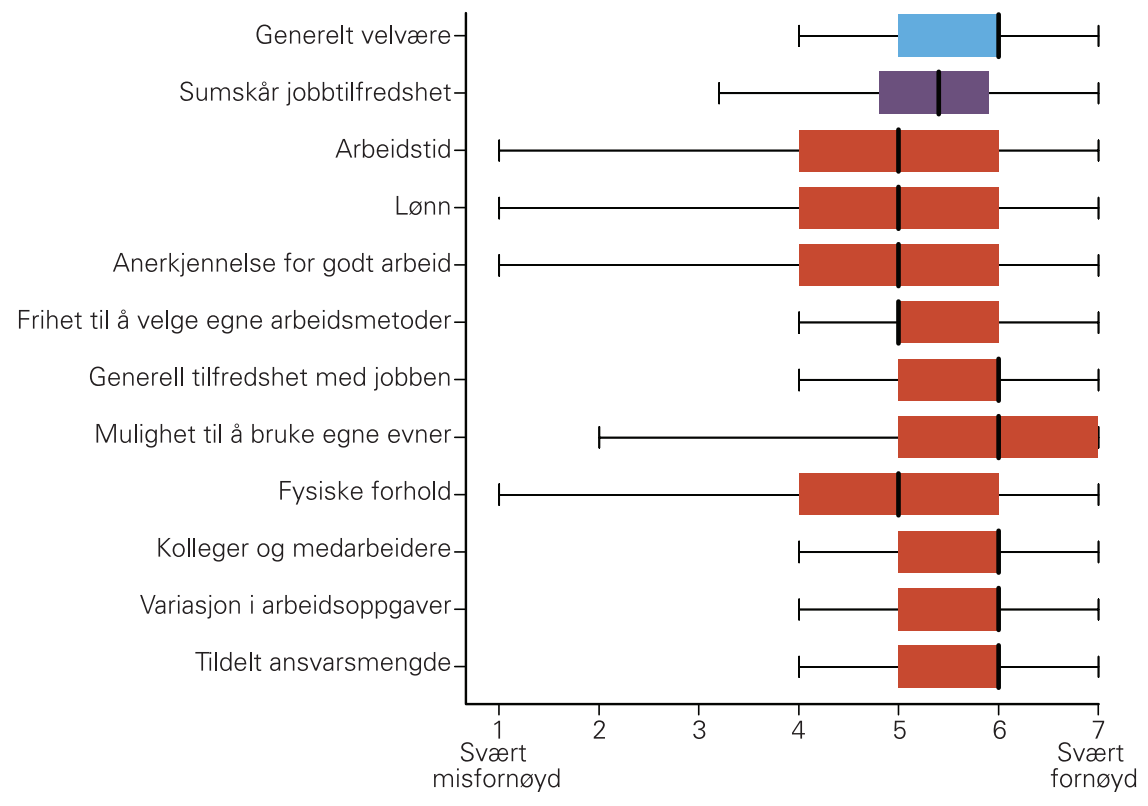

Figur 1 Boksplott av det generelle velværemålet, sumskår for jobbtilfredshet, samt de ti enkeltspørsmålene i jobbtilfredshetsskalaen Job Satisfaction Scale, alle på en skala fra 1 (svært misfornøyd) til 7 (svært fornøyd). Resultater fra et utvalg norske leger i 2008 ( $n=1040)$. Tykk vertikal strek angir median, boksene er området fra 25- til 75-prosentilen

Resultatene fra den lineære regresjonsmodellen med samlet jobbtilfredshet som responsvariabel er vist $i$ tabell 3. Det å ha en bistilling (eller flere) bidro til å øke jobbtilfredsheten, det samme gjorde opplevelsen av å være faglig oppdatert. Lang samlet arbeidstid hadde også i denne modellen en svak negativ effekt.

\section{Generell tilfredshet}

Gjennomsnittlig generell tilfredshet var 5,33, men svarene var så (positivt) skjevfordelte at

Tabell 2 Gjennomsnittsverdier på spørsmål om hvor fornøyd et utvalg norske leger er med lønn og arbeidstid i 2008. Skala fra 1 (svært misfornøyd) til 7 (svært fornøyd)

\begin{tabular}{lrc} 
«l hvilken grad er du fornøyd med lønnen din?» & Antall & $\begin{array}{c}\text { Gjennomsnitt } \\
\text { (95\% konfidensintervall) }\end{array}$ \\
\hline Privatpraktiserende spesialister & 65 & $5,85(5,58-6,11)$ \\
\hline Allmennleger & 273 & $5,40(5,24-5,56)$ \\
\hline Administrasjon & 41 & $5,32(4,95-5,68)$ \\
\hline Sykehusleger & 585 & $4,74(4,63-4,85)$ \\
\hline Annet & 29 & $4,62(4,10-5,14)$ \\
\hline Forskere & 65 & $3,98(3,55-4,41)$ \\
\hline Totalt & 1058 & $4,95(4,86-5,04)$ \\
«l hvilken grad er du fornøyd med arbeidstiden din?» & & \\
Privatpraktiserende spesialister & 65 & $5,43(5,07-5,79)$ \\
\hline Administrasjon & 41 & $5,27(4,83-5,70)$ \\
\hline Forskere & 65 & $4,97(4,59-5,35)$ \\
\hline Annet & 29 & $4,83(4,22-5,44)$ \\
\hline Allmennleger & 272 & $4,56(4,36-4,76)$ \\
Sykehusleger & 587 & $4,45(4,34-4,57)$ \\
Totalt & 1059 & $4,61(4,52-4,71)$
\end{tabular}

tistisk signifikante forskjeller kun mellom jobbkategorier, særlig fordi de privatpraktiserende spesialistene lå betydelig over de andre kollegene i generelt velvære. Mellom de fem geografiske regionene var det relativt store, men ikke statistisk signifikante forskjeller. Region 2 (Buskerud, Vestfold, Telemark, Aust-Agder, Vest-Agder) lå høyest, mens region 5 (Nordland, Troms og Finnmark) lå lavest (data ikke vist).

\section{Diskusjon}

Norske leger har en høy jobbtilfredshet. Tilfredshet med tilværelsen generelt og jobbtilfredshet i enda større grad, økte med økende alder. Privatpraktiserende spesialister utmerket seg med svært høy jobbtilfredshet. Sykehusleger var mindre tilfreds med arbeidstiden enn andre legegrupper. Vurdert etter spesialitetsgrupper hadde samfunnsmedisinere og allmennmedisinere høyest jobbtilfredshet, mens leger i kirurgiske og indremedisinske fag hadde lavest jobbtilfredshet.

En spørreskjemaundersøkelse av denne typen har flere svakheter. For det første kan det at bare to av tre inviterte svarte, skape tvil om representativiteten selv om responsraten er høyere enn for de fleste tilsvarende undersøkelser fra utlandet. For det andre er validitet og reliabilitet problematisk. Det subjektive ved egenrapportert tilfredshet brukes iblant som argument mot sammenlikninger både mellom enkeltpersoner og grupper. Den britiske økonomen Richard Layard avviser dette argumentet og sammenlikner tilfredshet med smerte: «There is no difference between what people think they feel and what they «really» feel» (2). Bruken av et 30 år gammelt, velprøvd og internasjonalt akseptert skåringsverktøy (16) styrker dessuten validiteten og gir mulighet for internasjonale sammenlikninger. For det tredje kan ikke tverrsnittsundersøkelser påvise årsakssammenhenger. Påviste sammenhenger mellom legekarakteristika og tilfredshetsnivå må derfor tolkes med forsiktighet.

Hvor høyt er egentlig et jobbtilfredshetsnivå på 5,3 på en skala fra 1 til 7 ? I hvert fall betyr det at de fleste svarerne ligger på den positive side $\mathrm{i}$ forhold til et verken-ellermidtpunkt. Sammenliknet med utenlandske studier av legers jobbtilfredshet der Job Satisfaction Scale er brukt, er det også høyt $(15,18-20)$.

Over halvparten av legene anga meget høy generell tilfredshet ( 6 eller 7 på en skala fra 1 til 7). Det er en høyere andel enn Tyssen og medarbeidere fant $i$ sitt legemateriale, som bare omfattet forholdsvis unge leger, og er på linje med det nivået de angir fra en sammenliknbar allmennbefolking i NordTrøndelag (12). Legenes generelle tilfredshet angitt på en sjudelt skala, kan ikke uten videre sammenliknes med Norsk Monitors spørsmål «Hvor fornøyd er du med din egen tilværelse?» som har fem svaralternativer (1). Men basert på Helleviks metode for til- 
Tabell 3 Multivariat lineær regresjonsmodell som viser samtidige effekter av forskjellige forhold på jobbtilfredshet. Resultater fra et utvalg norske leger i 2008 ( $n=864$ )

\begin{tabular}{lccc} 
& $\begin{array}{c}\text { Regresjons- } \\
\text { koeffisient }\left(\beta_{1}\right)\end{array}$ & Standardfeil & P-verdi \\
\hline Kjønn (mann) & $-0,02$ & 0,07 & 0,76 \\
\hline Alder i 2008 & 0,01 & 0,003 & $<0,001$ \\
\hline Antall barn & $-0,01$ & 0,03 & 0,73 \\
\hline Partner lege & $-0,02$ & 0,07 & 0,76 \\
\hline Bistilling & 0,19 & 0,06 & 0,002 \\
\hline Tid på faglig oppdatering & $-0,02$ & 0,01 & 0,078 \\
\hline Er faglig oppdatert & 0,31 & 0,07 & $<0,001$ \\
\hline Samlet arbeidstid & $-0,008$ & 0,003 & 0,007 \\
\hline Konstantledd & 4,8 & 0,2 & $<0,001$
\end{tabular}

fredshetsberegning synes legene å ha et tilfredshetsnivå over det gjennomsnittlige i den norske befolkning.

Privatpraktiserende spesialisters høye jobbtilfredshet avspeiler sannsynligvis både faglig og tidsmessig autonomi og gode økonomiske vilkår. Det er heller ikke overraskende at forskere er misfornøyd med lønnen. Allmennlegers høyere jobbtilfredshet enn sykehusleger (13) bekreftes også i denne undersøkelsen, og har sannsynligvis samme årsaker som de privatpraktiserende spesialistenes tilfredshet. At lang arbeidstid er assosiert med lavere tilfredshet, mens bistilling(er) er assosiert med høyere tilfredshet kan virke paradoksalt, men kan igjen ha sammenheng med nettopp autonomi. Selvvalgte tilleggsoppgaver som også gir større arbeidsvariasjon, har en annen effekt enn mer eller mindre pålagt overtid.

Analyser av den antatt økende profesjonsmisnøyen blant leger har pekt på mulige årsaker både innenfor og utenfor legestandens egne rekker (21). Pasienters, myndigheters og mediers endrede og mer kritiske holdning til legene regnes som eksterne faktorer, mens et sterkt økende antall leger og en større heterogenitet i legegruppen regnes som interne faktorer. Tidligere tiders mer eller mindre automatiske autoritet er blitt borte, og legerollen er blitt vanskeligere. Et økende tidspress er også blitt brukt som forklaring på den angivelige misnøyen (5). Tilfredshet i seg selv kan også sies å være politisk ukorrekt i dagens samfunn, i særdeleshet i helsesektoren der det alltid vil være forbedringspotensial både overfor enkeltpasienter og på systemnivå (8).

Når vi, i motsetning til det som synes å være den allmenne oppfatning, finner en høy grad av jobbtilfredshet, motbeviser ikke det noen av disse utfordringene for legestanden. Men funnene peker mot en grunnleggende profesjonsidentitet og tilfredshet som bygger på indre verdier mer enn på ytre forhold.

Oppgitte interessekonflikter: Ingen

\section{Litteratur}

1. Hellevik O. Jakten på den norske lykken. Oslo: Universitetsforlaget, 2008

2. Layard R. Happiness. Lessons from a new science. New York: Penguin, 2005.

3. Delamoth T. Happiness. BMJ 2005; 331: 1489-90

4. Kassirer J. Doctor discontent. N Engl J Med 1998 339: 1543-5.

5. Zuger A. Dissatisfaction with medical practice. N Engl J Med 2004; 350: 69-75.
6. BMJ Survey: why are doctors so unhappy? bmj.com/cgi/content/full/322/7294/DC4 (7.10.2009).

7. Smith R. Why are doctors so unhappy? BMJ 2001; 322: 1073-4.

8. Nylenna M. Er tilfredshet en trussel? Legelivet er bedre enn sitt rykte. I: Nylenna M, Jacobsen G, red Legerollens mange muligheter. Oslo: Gyldendal Akademisk, 2004.

9. Mechanic D. Physician discontent. Challenges and opportunities. JAMA 2003; 290: 941-6.

10. Hofoss D, Nord E. Norske leger - velstående og velansett, men ikke spesielt lykkelige. Tidsskr Nor Lægeforen 1997: 117: 3476-81.

11. Finset KB, Gude T, Hem E et al. Which young physicians are satisfied with their work? A prospective nationwide study in Norway. BMC Med Educ 2005: 5: 19.

12. Tyssen R, Hem E, Gude T et al. Lower life satisfac tion in physicians compared with a general population sample: a 10-year longitudinal, nationwide study of course and predictors. Soc Psychiatry Psychiatr Epidemiol 2009; 44: 47-54.

13. Nylenna M, Gulbrandsen P. Førde R et al. Unhappy doctors? A longitudinal study of life and job satisfaction among Norwegian doctors 1994-2002. BMC Health Serv Res 2005; 5: 44.

14. Nylenna M, Gulbrandsen P. Førde R et al. Job satisfaction among Norwegian general practitioners. Scand J Prim Health Care 2005; 23: 198-202.

15. Rosta J, Nylenna M, Aasland OG. Job satisfaction among hospital doctors in Norway and Germany. A comparative study on national samples. Scand J Public Health 2009; 37: 503-8.

16. Warr P, Cook J, Wall T. Scales for the measurement of some work attitudes and aspects of psychological well-being. J Occup Psychol 1979; 52 : 129-48.

17. Aasland OG, Nylenna M. Leger som røyker. Tidsskr Nor Lægeforen 1997; 117: 332-7.

18. Buciuniene I, Blazeviciene A, Bliudziute E. Health care reform and job satisfaction of primary health care physicians in Lithuania. BMC Fam Pract 2005, 6: 10

19. Sutherland VJ, Cooper CL. Job stress, satisfaction, and mental health among general practitioners before and after introduction of new contract. BM 1992; 304: 1545-8.

20. Whalley D, Gravelle H, Sibbald B. Effect of the new contract on GPs' working lives and perceptions of quality of care: a longitudinal survey. $\mathrm{Br} J \mathrm{Gen}$ Pract 2008; 58: 8-14.

21. McKinlay JB, Marceau LD. The end of the golden age of doctoring. Int J Health Serv 2002; 32: $379-416$

Manuskriptet ble mottatt 11.8. 2009 og godkjent 25.2. 2010. Medisinsk redaktør Mette Sagsveen. 